\title{
Long Noncoding RNAs in Aging
}

\section{Yang Wang*}

Department of Medical Microbiology and Immunology, Creighton University, Omaha, USA

*Corresponding author: Yang Wang, Department of Medical Microbiology and Immunology, School of Medicine, Creighton University, Omaha, USA, E-mail: ivywang@creighton.edu

Received date: September 02, 2016; Accepted date: November 14, 2016; Published date: November 16, 2016

Copyright: (c) 2016 Wang Y. This is an open-access article distributed under the terms of the Creative Commons Attribution License, which permits unrestricted use, distribution, and reproduction in any medium, provided the original author and source are credited.

Citation: Wang Y (2016) Long Noncoding RNAs in Aging. J Aging Sci 4: e123. doi:10.4172/2329-8847.1000e123

\section{Editor Note}

Aging increases the risk of disease and death. LncRNAs play important roles in age-related diseases, such as cardiovascular disease, neurodegenerative disorders and cancer. Recently, increasing evidences suggest that many long noncoding RNAs (lncRNAs) function through specific interactions with other cellular factors, namely proteins, DNA, and other RNA molecules. lncRNAs have been discovered and studied for many years, however their impact on protein expression programs has only been taken seriously in recent years [1].

Many long noncoding RNAs are reported to execute their cellular functions by associating with chromatin modifying factors. Gonzalez et al discovered that lncRNAs could alternatively splice by modulating chromatin signatures [2]. Some of the examples of lncRNAs are described here.

The H19 long noncoding RNA has been implicated in human genetic disorders and cancer by regulating the expression of different genes. Zou et al reported that $\mathrm{H} 19$ plays an important role in controlling the intestinal epithelial barrier function by serving as a precursor for microRNA 675 (miR-675) [3]. Holdt et al. found that ANRIL with atherosclerosis and Chr9p21 genotype are associated, however whether ANRIL expression is a marker or modulator of atherosclerosis at Chr9p21 genotype still need to be demonstrated [4]. Abdelmohsen et al. demonstrated that 7SL and HuR could affect gene expression by influencing p53, showing ncRNA 7SL is increased in cancer cells. They found that 7SL may be an effective target in the treatment of cancers with reduced p53 levels [5]. Yoon et al. found that HOTAIR is highly upregulated in senescent cells, causing rapid decay of targets to prevent premature senescence [6].
With advancing age, the body's ability declines to store energy, mobilize energy stores, sense changes in energy availability and utilization. The age-associated increases in adiposity, reduced pancreatic function, and loss of muscle mass lead to major pathologic conditions seen in the elderly [7]. LncRNAs are implicated in the aging process, age-related diseases and provide a suitable and effective way to design treatments in future.

\section{References}

1. Grammatikakis I, Panda AC, Abdelmohsen K, Gorospe M (2014) Long noncoding RNAs(lncRNAs) and the molecular hallmarks of aging. Aging (Albany NY) 6: 992-1009.

2. Gonzalez I, Munita R, Agirre E, Dittmer TA, Gysling K, et al. (2015) A IncRNA regulates alternative splicing via establishment of a splicingspecific chromatin signature. Nat Struct Mol Biol 22: 370-376.

3. Zou T, Jaladanki SK, Liu L, Xiao L, Chung HK, et al. (2016) H19 Long Noncoding RNA Regulates Intestinal Epithelial Barrier Function via MicroRNA 675 by Interacting with RNA-Binding Protein HuR. Mol Cell Biol 36: 1332-1341.

4. Holdt LM, Beutner F, Scholz M, Gielen S, Gäbel G, et al. (2010) ANRIL expression is associated with atherosclerosis risk at chromosome 9p21. Arterioscler Thromb Vasc Biol 20130: 620-627.

5. Abdelmohsen K, Panda AC, Kang MJ, Guo R, Kim J, et al. (2014) 7SL RNA represses p53 translation by competing with HuR. Nucleic Acids Res 42: 10099-10111.

6. Yoon JH, Abdelmohsen K, Kim J, Yang X, Martindale JL, et al. (2013) Scaffold function of long non-coding RNA HOTAIR in protein ubiquitination. Nat Commun 4: 2939.

7. Kim J, Kim KM, Noh JH, Yoon JH, Abdelmohsen K, et al. (2016) Long noncoding RNAs in diseases of aging. Biochim Biophys Acta 859: 209-221. 